\title{
YouthMap 5020! What should youth-centred web maps look like?
}

\author{
Sabine HENNIG and Robert VOGLER \\ IFFB Geoinformatik - Z_GIS, Universität Salzburg / Austria·sabine.hennig@sbg.ac.at
}

This contribution was double-blind reviewed as full paper.

\begin{abstract}
In recent years, web maps designed to meet the needs of particular user groups have gained in interest. A user group hereby mostly neglected are children including teenagers (i.e. the youth). While little is yet known about how this user group actually uses websites or how to design websites that will be easy for this user group to use, this is even truer for web maps, whose use has experienced a boom lately. Meanwhile, web maps have not only become a pervasive element on the Internet, but also a relevant means for education and teaching purposes. However, to address the rather special user group of children and teenagers known for being, e.g., impatient and quick to judge - it is necessary to exercise the design of web maps with care. But many questions still remain open with regard to youth-centred web maps. This refers to the requirements and needs of young people, including issues such as the type of device mainly and preferably used, map design, map content, as well as range and properties of functionalities. The project YouthMap 5020 aims to answer these questions. Therefore, the approach of participatory design, which is considered particularly useful when it comes to working with children, is used.
\end{abstract}

\section{Introduction, Background and Research Question}

User-centred (web) applications have gained overwhelming interest over the recent years. This is as true for user-centred web maps. Thus, for example, today we see web maps tailored to the demand of cyclists, tourists, wheelchair drivers, and the visually impaired. However, in regard to user-centred web maps, a group that has often and mostly been left behind are children and teenagers, i.e. the youth (see e.g. ZEISING \& KATTERFELDT 2013).

There still remains little knowledge about how children actually use websites or how to design websites that will be easy for them to use. Even less knowledge exists on how children use web maps and on their requirements directed towards web maps. Most of the scarcely available information originates from a study done by the Nielson Usability Group (URL 5, URL 6). However, one fact is for sure: Childrens' and teenagers' requirements on web applications as well as on web maps differ remarkably from those of adults (FRIEDRICH 2000, URL 2, URL 5, URL 10).

This knowledge gap is quite surprising insofar as the youth (also called digital natives) makes up an increasingly large percentage of the population going online, and is therefore 
an important Internet user group. Furthermore, due to a number of reasons there is a clear demand for knowing childrens' requirements on web maps and for developing youthcentred prototypes. Some of these reasons are briefly outlined below.

Firstly, per se children have a strong and lively interest in maps. Besides their fascination for maps, being able to read maps is considered a key competency. It is a central cultural technique like reading and writing. Further, being enabled to use maps is a prerequisite to providing a natural science background. Thus, it is a general necessity that children must be supported in a targeted, suitable manner, to use and discover maps, what today especially refers to the use of web maps (see e.g. GRYL \& JEKEL 2012, ÖSTERREICHER 2005).

Secondly, regardless of the subject, the inclusion of geomedia (also encompassing the use of web maps) in school education took place in recent years (DONERT 2010, GRYL \& JEKEL 2012, KERSKI 2008). This is underlined, on the one hand, by the emergence of a number of GI education approaches such as spatial thinking (NRC 2006) or spatial citizenship (GRYL \& JEKEL 2012), which aim at putting competence models, teaching courses and materials at teachers' fingertips. On the other hand, industry sets focus on providing usable tools and data to teachers, to allow them to incorporate GI in teaching. A prominent case is the GI market leader ESRI, who has been engaged in fostering the use of spatial data in (formal) education for several years (see e.g. URL 8).

Thirdly, due to certain child development stages, children show particular Internet use behaviour and characteristics. Hence, children including teenagers are described as being quite impatient, judging sites quickly, and leaving a site immediately without coming back again if it is deemed no good, or using the application was not considered as fun (URL 5, URL 6, URL 9). It is therefore necessary to convince these users at a first glance. This can best be done by particularly designed, i.e. youth-centred applications.

Despite the facts outlined above, which clearly underline the need for youth-centred web maps, such applications are still missing, and there is a lack on guidelines or recommendations on youth-centred web map design. Research on what youth-centred web maps should look like is urgently required. Open questions refer to the type of devices mostly used and preferred by the youth, to map design, map content, as well as range and properties of functionalities. The project YouthMap 5020 faces the challenge of designing a youth-centred web map, and, among others, to provide answers to these questions.

\section{YouthMap 5020 Project Description}

YouthMap 5020 (http://www.youthmap5020.at) is a project funded by the Austrian Federal Ministry for Transport, Innovation and Technology (BMVIT) in context with the FFG program "Talente Regional" (https://www.ffg.at/talente-regional). The project, which started in May 2013 and which will end in October 2014, aims at creating a web map for the city of Salzburg (zip code 5020) tailored to the requirements of young people. The YouthMap 5020 will be implemented as an ArcGIS online web map application. Moreover, based on the experience gained while designing and implementing the map application, YouthMap 5020 recommendations and suggestions will be made publicly available, aiming to assist others in creating youth-centred web maps.

Therefore, the approach of participatory design is applied. This decision is owed to the fact that literature highlights participatory design as a strategy particularly valuable and useful 
when it comes to working with children and when it is necessary to directly and actively involve them in processes (KAUFMAN 2011, MULLER \& DRUIN 2012). In order to let kids participate in the design process, the consortium of the YouthMap 5020 project includes adults and teenagers as well. Partners, on the one hand, are six schools located in Salzburg; on the other hand they come from public administrations as well as the business and scientific sector. As outlined in Table 1, each partner performs specific tasks.

Tab. 1: YouthMap 5020 project consortium

\begin{tabular}{|c|c|c|}
\hline \multicolumn{2}{|l|}{ Partner } & \multirow{2}{*}{$\begin{array}{l}\text { Description on tasks and role } \\
\text { project lead, scientific support }\end{array}$} \\
\hline Scientific & IFFB-Z_GIS, University Salzburg & \\
\hline $\begin{array}{l}\text { Public } \\
\text { administration }\end{array}$ & City of Salzburg, youth office & $\begin{array}{l}\text { real-world project- and product connection (and } \\
\text { dissemination) }\end{array}$ \\
\hline Business & SynerGIS & $\begin{array}{l}\text { technological support (referring the use of ArcGIS } \\
\text { online) }\end{array}$ \\
\hline \multirow[t]{6}{*}{ Schools } & Handelsakademie 2 & \multirow{6}{*}{$\begin{array}{l}\text { development of the YouthMap } 5020 \text { web map } \\
\text { application: } \\
\text { requirements specification, data collection, } \\
\text { processing, management, map design and } \\
\text { implementation, testing and optimization }\end{array}$} \\
\hline & Bundesrealgymnasium & \\
\hline & Akademisches Gymnasium & \\
\hline & ABZ St. Josef & \\
\hline & Sonder-Pädagogisches Zentrum 1 & \\
\hline & Praxis-Volksschule $(\mathrm{PH})$ & \\
\hline
\end{tabular}

\section{The Youth - A Quite Special User Group}

The children and teenagers involved form a quite heterogeneous Internet user group, covering an age span of different development stages, as well as various levels of skills and knowledge. Here, it has to be pointed out that web design, including the design of web maps, must fit the children's development stages. As the rapidity of development varies depending on the individual child, and several developmental leaps might occur during few months time only, it is a very challenging task to realize websites and web map applications meeting the needs of kids. Easily, children are either overburdened or under-burdened. Thus, it is a relevant basis for the development of a youth-centred map to first and foremost define and narrow the user group.

Due to particular development stages, web design targets very narrow age groups when designing for children in a broad sense (URL 5, URL 6, URL 12):

- children in a strict sense ( 3 - 12 years old) encompassing

o young children (3-5 years old),

o mid-range children (6-8years old),

o older children ( $9-12$ years old), and

- teenagers (13-17 years old).

But what about web map design for different aged children? Here, it has to be outlined, that literature differs on the age from which children begin a more or less "self-determined" use of the Internet: Some highlight that five year old kids are already fascinated by the Internet (SELTMANN 2008, URL 2), others state that kids start using the Internet from the age of 7 (see e.g. URL 10). Further, as the use of web maps requires certain reading, especially map reading abilities (understand bird view perspective, abstraction etc.) and more skilled motoric capabilities are necessary for (fully) using mouse, keyboard, touch screen etc. 
(URL 2), this puts certain age-related and development stage related constraints on web map use. According to these statements, the YouthMap 5020 project focuses on teenagers, i.e. children being at least 12-13 years old (secondary education equivalent age).

\section{Methods for Youth-centred Web Map Development}

User-centred applications are characterized by being tailored to meet the needs and requirements of a specific user group. Accordingly, well-funded knowledge regarding the particular user group and their requirements is necessary. Therefore, software development processes pay growing attention to specify user requirements which help to determine product characteristics in more detail (RICHTER \& FLÜCKINGER 2007). This is also true for youth-centred applications. However, applications made for children and teenagers are often created only based on knowledge delivered by what others say, general assumptions on how kids supposedly behave, or, at best, on insights gained when designers observed their own children (URL 2, URL 5). But this is not enough. Literature highlights that in the case of youth-centred applications, relevant information can be gained by engaging young people actively in application design and development processes (URL 2). Based on these assumptions, the YouthMap 5020 development strategy relied not only on well-known software development processes, but also on the application of the participatory design approach. Methods were used that originate from and are applied in both realms as well as closely related fields (see Fig. 1 at the end of this section).

\subsection{Design and development strategies}

\section{Participatory design}

By definition, participatory design is a form of a user-centred design approach. It is a method that allows assessing, designing, and developing systems, while attention is placed on the active involvement of its users. Thereto, it is closely related to participatory decision-making processes. It aims to ensure that the product design meets the needs of the user group and is usable to them (URL 3, URL 4).

Regarding the involvement of teenagers, the approach focuses on engaging young people to take part in the design and development process of a project or product. This allows informing program design and implementation, as well as to ensure that activities are responsive to the youth's needs and the on-the-ground basis (KAUFMAN 2011). With the belief that more appropriate solutions can be found, researchers seek to give children a voice in the design of new technologies (MULLER \& DRUIN 2012).

\section{Software development process}

The design and implementation of the YouthMap 5020 map product follows well-known and broadly used state-of-the-art software development processes, which are broken down in several stages such as IT project management, conception, design, creation, and implementation (see e.g. BALZERT 2000, SOMMER-VILLE 2007).

The dissection into separated phases provides the advantage that particular attention can be paid to identify, describe and fully recognize user requirements. This is even more relevant since analysing users and their requirements is seen as a pivotal aspect for developing user- 
centric software applications. Moreover, user requirements show effect on the entire software development process and trigger all further development steps. It bases on a wide variety of methods. They encompass user surveys, interviews, identifying target user groups, running through scenarios of use, task analysis, observations, analyses of documents and analogue systems, common working meetings, and analogue methods (NIELSEN 1994, RICHTER \& FLÜCKIGNER 2007).

\subsection{Applied techniques and methods}

From the wide range of methods outlined in the context of participatory design as well as software development, several were applied in the YouthMap 5020 project. Therefore, workshops, working meetings, and pupil internships provided the framework (Fig. 1).

\section{Questionnaire}

The main source of information on user requirements regarding the YouthMap 5020 map application was a survey conducted in autumn and winter 2013/2014. According to the principles of empirical social research, the questionnaire was implemented using the Internet survey tool SurveyMonkey (www.surveymonkey.com). The questionnaire consisted of 26 questions focusing on socio-demographic data (age, sex, school education, place of residence), preferred map design (background map, symbols), map content (spatial data, context information), range and properties of functionalities (social media services, map navigation, search of addresses and locations etc.), etc.

The survey was not only created and spread by the pupils themselves using numerous communication channels (face-to-face, email, Facebook etc.), but also statistically analysed using MS Excel and IBM SPSS. Since the questionnaire was developed by the pupils themselves, information on the user group and their requirements was on the one hand gained through the survey; on the other hand the questionnaire elaboration process (discussions, comments, decision-making in cooperation with the pupils etc.) revealed lots of interesting aspects.

\section{Observation}

To provide the pupils with some background information regarding the use and development processes of web maps, workshops were performed with the different school grades (see Tab. 1). Thus, pupils got an introduction to ArcGIS online and experienced what it looks like to work with web maps as well as what has to be done and considered when designing and implementing a web map, i.e. web map application. Observing the pupils in the work-process, as well as their presentations and discussions of the maps they had produced resulted in a valuable opportunity to receive relevant information about the user group.

\section{Literature review and application analysis}

Some literature exists, although not abundantly, regarding web design and usability recommendations focusing on the needs of children. The situation is even worse regarding the design and use of web maps. However, general information on these users (children and teenagers), characteristics, abilities, capabilities, as well as common computer and Internet use behaviour etc., is available. Further, some software systems, i.e. web (map) applications developed for children exist. Thus, a literature review and application analysis have been, to a certain degree, a relevant information source. 


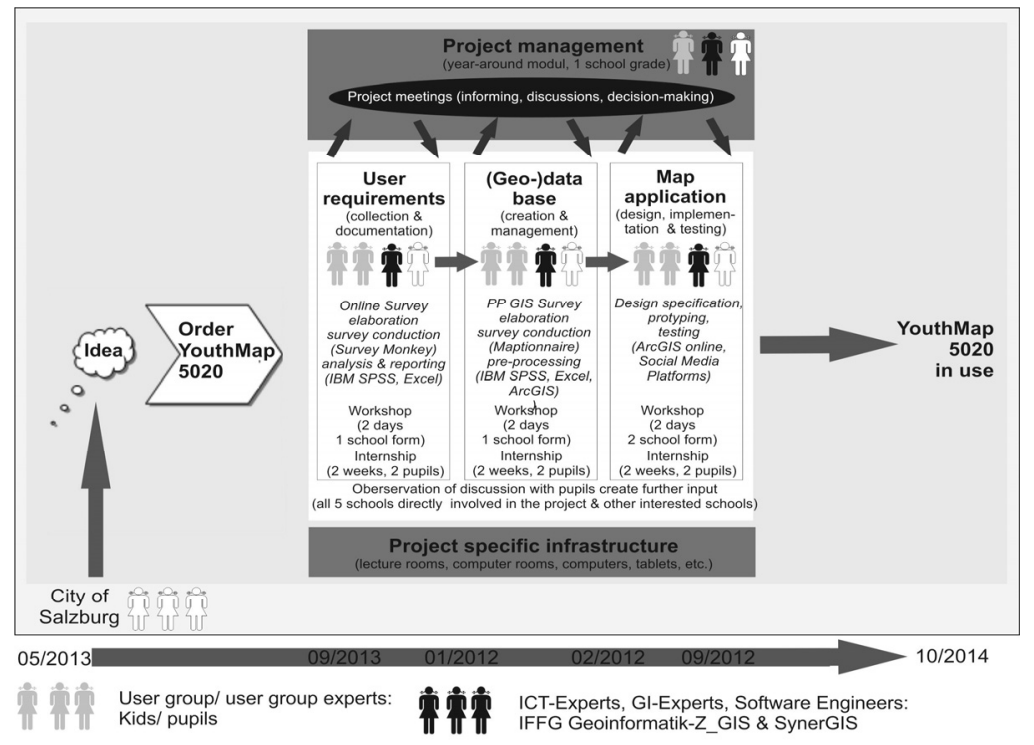

Fig. 1: YouthMap 5020 development process and strategy

\section{$5 \quad$ Selected Results}

Even though the project is still in progress, we can already present and discuss some first results gained from the questionnaire elaboration, the questioning itself (having 502 valid responses), from discussions with pupils, and from observing them while working with ArcGIS online. The results were enriched by findings from a literature review and analysis of other applications. Universally valid, it has to be highlighted that certain web map requirements are often related to children's particular characteristics as well as skill sets, abilities, and capabilities, depending on the development stage, which can be built on while they grow up and learn (URL 2, URL 6, URL 9, URL 11). This refers e.g. to low patience level, (over)confidence in their web abilities, not fully developed motoric capabilities, long reaction time, reduced attention span, insufficient reading skills, and less sophisticated research strategies.

\subsection{Map content and functionalities}

Generally, teenagers want to learn and play, but not to work with the computer (URL 2). Thus it is important for web maps, as with web applications, to avoid boring them with too educational content, and thereby on the contrary not to get in the way of entertainment overload (URL 6).

\section{Geodata and geo services}

With regard to background maps, the questionnaire reveals by an overwhelming majority that street maps are the most popular among the user group (83\%). Despite this number, the youth obviously gets really excited about satellite images. This was observed while letting 
the pupils work with ArcGIS online. Hence, youth-centred maps should offer a least two switchable types of background maps.

Besides objects typically presented in city maps - such as parks and gardens, water bodies (lakes, rivers etc.), different types of streets, squares and places, points of interest (museums, shops, hotels etc.), public buildings (churches, schools, city hall etc.), features referring to public means of transportation (bus routes and stops etc.), bridges and tunnels (HORSTMANN et al. 2006, ZENG \& WEBER 2010) - young people require particular information. Most important to the youth are shopping malls $(36 \%)$. But also parks and green places $(31 \%)$, as well as public places $(25 \%)$ are considered rather relevant. Moreover there are a number of unofficial fairly youth specific locations used to meet and/ or to just "chill out", which are of pivotal importance to the user group. Regarding all locations, the youth asks for certain additional information describing and characterizing the particular locations (Table 2). Surprising was that the youth indicated high interest in knowing safe places, i.e. getting information on the safety situation of particular locations, police stations, as well as hospitals.

Tab. 2: Overview on the information demand on the part of the youth

\begin{tabular}{|l|l|l|}
\hline & Information categories \\
\hline Geodata & $\begin{array}{l}\text { "leisure time sites": shopping malls, youth } \\
\text { meeting/ chilling points } \\
\text { restaurants, i.e. places to eat; } \\
\text { coffee shops, bars, } \\
\text { locations to party } \\
\text { parks and green spaces } \\
\text { cultural sites } \\
\text { locations to do sports }\end{array}$ & $\begin{array}{l}\text { bus stations and taxi stands } \\
\text { police stations and hospitals } \\
\text { WIFI-Hotspots } \\
\text { cash points, tobacconist } \\
\text { toilets } \\
\text { schools } \\
\text { etc. }\end{array}$ \\
\hline $\begin{array}{l}\text { Additional } \\
\text { related } \\
\text { information }\end{array}$ & $\begin{array}{l}\text { opening hours } \\
\text { prices (admission prices, beverages etc.) } \\
\text { smoking areas, i.e. smoking allowed } \\
\text { age restriction } \\
\text { availability of free wireless networks } \\
\text { peculiarities }\end{array}$ & $\begin{array}{l}\text { events, i.e. event calendar, } \\
\text { music type } \\
\text { address and phone number } \\
\text { feeling of safety } \\
\text { etc. }\end{array}$ \\
\hline
\end{tabular}

Generally, multimedia (picture, videos and audio files) and hyperlinks can be leveraged to impart additional information. These elements are typically arranged in information windows, i.e. pop-ups. Such elements are welcome by the user group. However, while pictures are highly desired, web links are less popular. This might be seen in context with the fact that children have difficulties to recognize links as such. For them blue underlined text doesn't vary from other text (URL 2). Thus, it is necessary to provide the information wanted (Table 2; normally available at websites) in a more suitable way. Further, all textual information should by presented in understandable text with short sentences and abundant paragraphs not using a too tiny font size (URL 2, URL 6, URL 11, URL 13).

Finally, two types of (geo-)services are in high demand amongst the youth: routing services and public transportation system services. They should be implemented in the YouthMap 5020 web map product, or at least a link should be provided giving access to applications offering these services. 


\section{Functionalities}

Besides general functionalities known from web maps such as zoom, pan, and turning layer visibility on and/ or of etc., functionalities closely related to social media platforms are highly demanded. The majority of the respondents asked for embedding social networking services. This conforms to findings on kids' Internet use: Teenagers like forms for providing feedback or asking questions, online voting, features for sharing pictures and stories, message boards (URL 6, URL 9). Despite this, most of the respondents want to use the YouthMap 5020 web map without the need of creating an own profile. This is a tendency also underlined in the literature: Children do not want to register or create profiles while using web applications (raised awareness on Internet security issues). Further, the target group is more or less evenly divided in being interested in other users' comments and ratings on map features or not being interested. But no one really requests opportunities for sharing own ratings and comments, i.e. adding own information.

In a nutshell, the youth clearly underpins the need for web maps that extend geocommunication with social media functionalities (HENNIG et al. 2011). Young people who are familiar with and accustomed to the use and leverage of social media ask - more than other user groups - for a map combining features well-known and beloved in social media applications. Hence, the traditional (web) map needs to be extended by the involvement of well selected and implemented social networking services. When implementing functionalities, one must be aware, that the youth prefers simple, straight forward processes such as point and click (URL 2). The mouse is the preferred device (URL 14).

\subsection{GUI and map and design}

Questions on the web map design refer to the map object, as well as the GUI that the map object is embedded in. Both the map and GUI should follow standard design guidelines.

Like for other user groups, it is important for children and teenagers that GUI and map are kept simple and consistent. Characteristics, abilities and capabilities of the user group outlined above - require simple sites, a design which is clearly laid out and well-arranged and content that is well-structured (URL 6, URL 9). To avoid information overload and support a well-readable map picture for the user group, it is suggested to distinguish winter and summer content and information suitable for different age-groups.

Regarding the layout, it is known that the youth likes it colourful. This matches web design guidelines for children which outline that kids like colours (bright, vivid colours) as well as pictures (URL 1, URL 7). This has been emphasized by our questionnaire, too. Despite the desire for cool looking graphics and a "snappy" look of the map and GUI (deemed not boring by kids), it must be guaranteed that symbols are easy to understand and icons are easy to identify with clear functions (URL 2, URL 6, URL 13).

\section{Conclusion and Outlook}

The YouthMap 5020 project is still in progress. Nevertheless, the work already conducted delivered interesting results on the use and design of web maps on behalf of children and young people. Thereby, the project fully benefits from today's shift in attitude from designing for users to one of designing with users (SANDERS \& SONICRIM 2002). 
Besides providing insight into the youth's requirements on web maps, several more advantages result from the YouthMap 5020 project. This refers to the field of urban planning (describing the youth's living conditions; suggestions for improvement etc.), education and teaching (information to provide more suitable geo-media tools differing from those used by adults), youth development principles and practices (young people work in partnership with adults, which delivers relevant input) and GI product development (contribution in terms of combining diverse knowledge to make better services and products).

\section{References}

BALZERT, H. (2000), Lehrbuch der Software-Technik. Spektrum Akademischer Verlag.

DONERT, K. (Ed.) (2010), Using geoinformation in European geography education. Rome.

FRIEDRICH, B. (2000), "Wien für Kinder" - Entwurf eines Kartographischen Informationssystems für eine spezifische Benutzergruppe. In: Strobl, J., Blaschke, T. \& Griesebner, G. (Hrsg.), Angewandte Geoinformatik 2000. Heidelberg, Wichmann. http://www.agit.at/php_files/myagit/papers/2000/friedrich_EA_7.pdf (20.1.2014).

GRYL, I. \& JEKEL, T. (2012), Re-centering GI in secondray education. Towards a spatial citizenship approach. Cartographica, 1/2012, 2-12.

Gryl, I., Jekel, T. \& Donert, K. (2010), GI and Spatial Citizenship. In, Jekel, T., Koller, A., Donert, K. \& Vogler, R. (Eds.), Learning with Geoinformation V. Heidelberg, Wichmann, 2-11.

HenNig, S. (2013), YouthMap 5020. Participatory Design für erfolgreiche, nutzerzentrierte Kartenapplikationen. Arc Aktuell, 16-17.

Hennig, S., Vogler, R. \& JeKel, T. (2011), Web - 2.0 Anwendungen zur partizipativen Planung und sozialen Geokommunikation: Ihr seid die Planer. In: GIS.Science. Die Zeitschrift für Geoinformatik. 3/2011, 65-74.

Horstmann, M., Heuten, W., Miene, A. \& Boll, S. (2006), Automatic Annotation of Geographic Maps. In: Proceeding ICCHP'06 Proceedings of the 10th international conference on Computers Helping People with Special Needs. Berlin/Heidelberg, Springer, 69-76.

Kaufman, L. R. (2011), Community Youth Mapping. A Tool for Youth Participation and Program Design. Education Development Center, Inc. http://www.equip123.net/docs/e3-CYM.pdf (20.01.2014).

KERSKI, J. J. (2003), The implementation and effectiveness of Geographic Information Systems technology and methods in secondary education. In: Journal of Geography, 3/2003, 128-137.

Muller, M. J. \& Druin, A. (2012), Participatory Design; The third space in HCI. In, J. Jacko (ed.), The Human-Computer Interaction Handbook. Hillsdale, NJ, Lawrence Erlbaum Associates.

NiELSEN, J. (1994), Usability Engineering. San Francisco, Morgan Kaufmann Publishers.

NRC - NATIONAL RESEARCH COUNCIL (2006), Learning to think spatially: GIS as a Support System in the K-12 Curriculum. Washington DC.

ÖsterReICHER, H. (2005), Wissen wo's langgeht! Mit Kindern Karten und Stadtpläne erkunden. Kindergarten heute, 8/2005, 26-31.

www.kindergartnepaedagogik.de/1529.html (20.01.2014). 
RICHTER, M. \& FlÜCKINGER, M. (2007), Usability Engineering kompakt. München, Spektrum.

SANDERS, E. \& SONICRIM (2002), From User-Centred to Participatory Design Approaches. In: Design and the Social Sciences, ed. by J. FRASCARA. Taylor \& Francis Books Limited.

Seltmann, S. (2008), Kindgerechtes Webdesign und Usability. Master thesis.

SOMMERVILLE, J. (2007), Software Engineering. Pearson Studium.

ZEISING, A. \& KATtERFELDT, E.-S. (2013), Where is the 'like' button? Going beyond usability when designing for and with teens. CHI'13, April 27 - May 2, 2013, Paris. http://www.chici.org/teens2013/papers/chi2013-w22-paper13.pdf (08.01.2014).

ZENG, L. \& Weber, G. (2010), Accessible Maps for the Visually Impaired. http://ceurws.org/Vol-792/Zeng.pdf (20.01.2014).

URL 1: http://www.designmadeingermany.de/magazin/4/usability-kinder/ (8.1.2014)

URL 2: http:/www.drweb.de/magazin/kids-usability-websites-kindergerecht-gestalten/ (8.1.2014)

URL 3: $\quad$ cpsr.org/prevsite/program/workplace/PD.html (8.1.2014)

URL 4: edutechwiki.unige.ch/en/Participatory_design (8.1.2014)

URL 5: $\quad$ www.nngroup.com/articles/childrens-websites-usability-issues (8.1.2014)

URL 6: www.nngroup.com/articles/usability-of websites-for-teenagers (8.1.2014)

URL 7: www.smashingmagazine.com/2009/11/27/designing-websites-for-kids-trendsand-best-practices (8.1.2014)

URL 8: http://www.esri.de/branchen/bildung-und-forschung/gis-macht-schule (8.1.2014)

URL 9: http://www.usability.ch/bn/news/usability-ux-news/detail/alertbox-teenagerusability-website-design-fuer-jugendliche.html (8.1.2014)

URL 10: http://ec.europa.eu/digital-agenda/en/creating-better-internet-kids (8.1.2014)

URL 11: www.fit-fuer-usability.de/archiv/usability-kriterien-fuer-teenager (8.1.2014)

URL 12: https://wwww.msu.edu/ webbsuza/atw/graceb (8.1.2014)

URL 13: http://etec.ctlt.ubc.ca/510wiki/Effective_Web_Design_for-a_Teenage_Audience (8.1.2014)

URL 14: http://www.wiu.edu/thecenter/articles/engag.html (8.1.2014) 